\title{
To modeling admixtures influence on the size effects in a thin film
}

\author{
Bozhenko B. $^{1,2}$, Nahirnyj T. ${ }^{1,3}$, Tchervinka K. ${ }^{4}$ \\ ${ }^{1}$ Centre of Mathematical Modeling of IAPMM named after Ya.S.Pidstryhach \\ 15 D. Dudaev str., 79005, Lviv, Ukraine \\ ${ }^{2}$ Opole University of Technology \\ ul. Luboszycka 3, 45-036 Opole, Poland \\ ${ }^{3}$ Faculty of Mechanical Engineering, University of Zielona Góra \\ 4 Prof. Szafran str., 65-516 Zielona Góra, Poland \\ ${ }^{4}$ Ivan Franko National University of Lviv \\ 1 Universytetska str., 79000 Lviv, Ukraine
}

(Received 28 December 2015)

\begin{abstract}
There are formulated the key systems of equation describing structurally nonhomogeneous two-component solid solutions. As the key functions there are chosen the stress tensor (displacement vector) and the densities of admixture and skeleton. On this basis the nearsurface nonhomogeneity densities of skeleton and admixture, stresses and size effects of surface tension and intensity of the power load causing the thin film fracture are studied. The attention is paid to the admixture influence on size effects.
\end{abstract}

Keywords: solid solutions, near-surface non-homogeneity, thin films, size effects

2000 MSC: 74A15, 74A50, 74E05, 74K35, 74N25

UDC: $[539.3+532.72]: 532.68$

\section{Induction}

It is known that admixtures can significantly change the material properties and thus affect the parameters of reliability and strength of specific structural elements and devices [1-3]. Therefore it is important to construct and study the mathematical models describing the interrelated fields in solid solutions in particular taking into account the effects of structural and near-surface non-homogeneities. The latter are important to model and predict the behavior of nano elements that are widely used in modern engineering $[4,5]$.

One of effective approaches used to describe interrelated fields in the nano elements is local gradient approach in thermomechanics [6-8]. The approach is based on the main principles of irreversible thermodynamics and nonlinear mechanics. Within the approach into the space of state parameters along with usually accepted parameters additionally there are introduced the chemical potential and the density; also the mass balance equation is expanded on local non-homogeneous systems. Herewith the density and chemical potential are conjugated state parameters. According to this approach, there have been built a number of models [9] and a wide range of studies has been conducted concerning near-surface non-homogeneity and related size effects, including the ones of surface stress, strength, surface tension and so on. While formulating boundary value problems the value of the chemical potential was usually stated at the body surface. It was considered that this value can be determined using the comparison of body mass at the initial and actual times. Further studies have shown that such assumption does not allow to correctly identify the surface value of chemical potential. In [10] the formulation of boundary condition for the density is reasoned. The density value at the surface is related to the roughness (geometric non-homogeneity) of the real body surface. It is also shown that the value of the chemical potential, which is set up at the surface of the body is uniquely determined by its physical and geometrical characteristics and parameters of the environment. 
In this paper for two-component locally non-homogeneous solid solution there is presented the key system of equations in terms of displacement vector (stress tensor), the densities of the skeleton and admixture. The influence of admixtures on the near-surface non-homogeneity in the thin film as well as the effects caused by local non-homogeneity are studied.

\section{Basic relations}

We consider a deformable two-component solid with basic processes of thermal conductivity, deformation and diffusion taking place in it. Neglecting the convective component of fluxes the total energy $E$ balance equation in the local form can be written as

$$
\frac{\partial E}{\partial \tau}=\nabla \cdot\left(\boldsymbol{\sigma} \cdot \boldsymbol{v}-T \boldsymbol{j}_{s}-H_{0} \boldsymbol{j}_{m 0}-H_{1} \boldsymbol{j}_{m 1}\right),
$$

where $\boldsymbol{\sigma}$ is the Cauchy stress tensor, $\boldsymbol{v}$ is the velocity vector, $T, H_{0}, H_{1}$ are the absolute temperature and chemical potentials of skeleton and admixture, $\boldsymbol{j}_{s}, \boldsymbol{j}_{m 0}, \boldsymbol{j}_{m 1}$ are vectors of entropy flux and fluxes of skeleton and admixture masses, $\tau$ denotes the time, $\boldsymbol{\nabla}$ is the del operator.

Considering in the equation (1) representation of the total energy $E$ as the sum of internal $U$ and kinetic $K$ energies and the balance equations of momentum, entropy, mass balance equations for subsystems of skeleton and admixture in the form

$$
\begin{aligned}
& \frac{\partial \boldsymbol{k}_{v}}{\partial \tau}=\nabla \cdot \boldsymbol{\sigma}, \\
& \frac{\partial S}{\partial \tau}=-\nabla \cdot \boldsymbol{j}_{s}+\sigma_{s}, \quad \sigma_{s} \geqslant 0, \\
& \frac{\partial \rho_{i}}{\partial \tau}=-\nabla \cdot \boldsymbol{j}_{m i}, \quad i=0,1,
\end{aligned}
$$

along with relation for the kinetic energy increase

$$
d K=\boldsymbol{v} \cdot d \boldsymbol{k}_{v},
$$

we obtain the following equation of the internal energy balance

$$
\begin{aligned}
\frac{\partial U}{\partial \tau}= & \boldsymbol{\sigma}: \frac{\partial \mathbf{e}}{\partial \tau}+T \frac{\partial S}{\partial \tau}+H_{0} \frac{\partial \rho_{0}}{\partial \tau}+H_{1} \frac{\partial \rho_{1}}{\partial \tau} \\
& -T \sigma_{s}-\boldsymbol{j}_{s} \cdot \nabla T-\boldsymbol{j}_{m 0} \cdot \nabla H_{0}-\boldsymbol{j}_{m 1} \cdot \nabla H_{1},
\end{aligned}
$$

where $\boldsymbol{k}_{v}$ is the momentum of mechanical motion, $S$ is the entropy, $\rho_{0}$ and $\rho_{1}$ are the densities of skeleton and admixtures, $\mathbf{e}$ is the strain tensor, $\sigma_{s}$ is the entropy production.

We suppose that the thermodynamic fluxes $\boldsymbol{j}_{s}, \boldsymbol{j}_{m 0}, \boldsymbol{j}_{m 1}$ dependences on the forces are functional. In the linear case for isotropic solids we can write

$$
\boldsymbol{j}_{i}=\mathcal{G}_{i s} *(-\nabla T)+\mathcal{G}_{i m 0} *\left(-\nabla H_{0}\right)+\mathcal{G}_{i m 1} *\left(-\nabla H_{1}\right),
$$

where

$$
\mathcal{G}_{i j} * \varphi=\int_{0}^{\tau} G_{i j}(\tau, \xi) \frac{\partial \varphi(\xi)}{\partial \xi} d \xi, \quad i, j=\{s, m 0, m 1\},
$$

and $G_{i j}(\tau, \xi)$ are influence functions.

For the local gradient approach in thermomechanics the influence function in relations (4) should reflect the formation of the material structure of the skeleton subsystem. Therefore, in the case of 
considered two-component solid solution for influence functions we accept such a form

$$
G_{i j}(\tau, \xi)=\left\{\begin{array}{lc}
-g_{m m} \delta(\tau-\xi)+g_{m 0 m 0}(\tau, 0), & i=j=m 0 \\
g_{i j}(\tau, 0), & \text { otherwise }
\end{array}\right.
$$

where $\delta(\cdot)$ is Dirac delta-function.

From (4), (5) we obtain the following expression of the fluxes

$$
\begin{aligned}
\boldsymbol{j}_{s} & =-g_{s s} \boldsymbol{\nabla} T-g_{s m 0} \boldsymbol{\nabla} H_{0}-g_{s m 1} \boldsymbol{\nabla} H_{1}, \\
\boldsymbol{j}_{m 0} & =g_{m m} \frac{\partial\left(\boldsymbol{\nabla} H_{0}\right)}{\partial \tau}-g_{m 0 s} \boldsymbol{\nabla} T-g_{m 0 m 0} \boldsymbol{\nabla} H_{0}-g_{m 0 m 1} \nabla H_{1}, \\
\boldsymbol{j}_{m 1} & =-g_{m 1 s} \boldsymbol{\nabla} T-g_{m 1 m 0} \boldsymbol{\nabla} H_{0}-g_{m 1 m 1} \boldsymbol{\nabla} H_{1} .
\end{aligned}
$$

The coefficients in the formula (6) may depend on parameters of the state. Thereafter we take the following representation of the coefficients in (6)

$$
\begin{gathered}
g_{s s}=\frac{\lambda_{s s}}{T}, \quad g_{m 0 m 0}=\frac{\lambda_{00}}{T}, \quad g_{m 1 m 1}=\frac{\lambda_{11}}{T}, \\
g_{s m 0}=g_{m 0 s}=\frac{\lambda_{s 0}}{T}, \quad g_{s m 1}=g_{m 1 s}=\frac{\lambda_{s 1}}{T}, \quad g_{m 0 m 1}=g_{m 1 m 0}=\frac{\lambda_{01}}{T} .
\end{gathered}
$$

Presentation (4), (5) allows to write the balance equations of entropy and masses in the form

$$
\begin{aligned}
& \frac{\partial S}{\partial \tau}=-\nabla \cdot \boldsymbol{j}_{s}+\sigma_{s}, \\
& \frac{\partial \rho_{1}}{\partial \tau}=-\nabla \cdot \boldsymbol{j}_{m}^{(1)}, \\
& \frac{\partial}{\partial \tau}\left(\rho_{0}+g_{m m} \nabla^{2} H_{0}\right)=-\nabla \cdot \boldsymbol{j}_{m}^{(0)},
\end{aligned}
$$

where

$$
\begin{aligned}
\boldsymbol{j}_{s} & =-\lambda_{s s} \frac{\nabla T}{T}-\lambda_{s 0} \frac{\nabla H_{0}}{T}-\lambda_{s 1} \frac{\nabla H_{1}}{T}, \\
\boldsymbol{j}_{m}^{(0)} & =-\lambda_{s 0} \frac{\boldsymbol{\nabla} T}{T}-\lambda_{00} \frac{\boldsymbol{\nabla} H_{0}}{T}-\lambda_{01} \frac{\boldsymbol{\nabla} H_{1}}{T}, \\
\boldsymbol{j}_{m}^{(1)} & =-\lambda_{s 1} \frac{\boldsymbol{\nabla} T}{T}-\lambda_{01} \frac{\boldsymbol{\nabla} H_{0}}{T}-\lambda_{11} \frac{\boldsymbol{\nabla} H_{1}}{T}, \\
\sigma_{s} & =-\frac{1}{T}\left(\boldsymbol{j}_{s} \cdot \nabla T+\boldsymbol{j}_{m}^{(0)} \cdot \nabla H_{0}+\boldsymbol{j}_{m}^{(1)} \cdot \nabla H_{1}\right) .
\end{aligned}
$$

The presentation along with (8) modifies the balance equation (3) to the form

$$
\frac{\partial G}{\partial \tau}=\boldsymbol{\sigma}: \frac{\partial \mathbf{e}}{\partial \tau}+T \frac{\partial S}{\partial \tau}+H_{0} \frac{\partial \rho_{0}}{\partial \tau}+H_{1} \frac{\partial \rho_{1}}{\partial \tau},
$$

where

$$
G=U+\frac{1}{2} g_{m m}\left(\nabla H_{0}\right) \cdot\left(\nabla H_{0}\right) .
$$

While studying the solid solutions along with systems of skeleton and admixture one considers a continuum of mass centers for which the mass flux is zero. Accepting

$$
\boldsymbol{j}_{m}=\boldsymbol{j}_{m}^{(0)}+\boldsymbol{j}_{m}^{(1)}
$$


the third equation of (7) can be replaced with such equation of mass balance of mass centers continuum

$$
\frac{\partial}{\partial \tau}\left(\rho_{0}+\rho_{1}+g_{m m} \nabla^{2} H_{0}\right)=0 .
$$

For potential description it could be argued that energy $G$ is defined in the space of entropy $S$, densities of skeleton and admixture subsystems $\rho_{0}, \rho_{1}$ and strain tensor $\mathbf{e}$,

$$
G=G\left(S, \rho_{0}, \rho_{1}, \mathbf{e}\right)
$$

and for the energy increase $d G$ the equation is held

$$
d G=T d S+H_{0} d \rho_{0}+H_{1} d \rho_{1}+\boldsymbol{\sigma}: d \mathbf{e} .
$$

The parameters conjugated to $S, \rho_{0}, \rho_{1}$, e are respectively temperature $T$, chemical potentials $H_{0}, H_{1}$ and stress tensor $\boldsymbol{\sigma}$.

Introducing energy $F$ with Legendre transformation

$$
F=G-T S
$$

from (11) we write the following state equations

$$
S=-\frac{\partial F}{\partial T}, \quad H_{0}=\frac{\partial F}{\partial \rho_{0}}, \quad H_{1}=\frac{\partial F}{\partial \rho_{1}}, \quad \boldsymbol{\sigma}=\frac{\partial F}{\partial \mathbf{e}} .
$$

Thus the energy $F$ is defined in the state parameter space consisting of temperature $T$, chemical potentials $H_{0}, H_{1}$ and strain tensor e

$$
F=F\left(T, \rho_{0}, \rho_{1}, \mathbf{e}\right) .
$$

We accept as a reference state the state of isotropic body free of force load with parameters

$$
T=T_{*}, \quad S=S_{*}, \quad H_{0}=H_{0 *}, \quad H_{1}=H_{1 *}, \quad \rho_{0}=\rho_{0 *}, \quad \rho_{1}=\rho_{1 *}, \quad \mathbf{e}=0, \quad \boldsymbol{\sigma}=0 .
$$

Further we take energy $F$ as a quadratic function in the space of basic parameter disturbances from the reference state

$$
\theta=T-T_{*}, \quad \rho_{0}-\rho_{0 *}, \quad \rho_{1}-\rho_{1 *}, \quad \mathbf{e}=\mathbf{e}-0,
$$

in the form

$$
\begin{aligned}
F= & F_{*}-S_{*} \theta+H_{0 *}\left(\rho_{0}-\rho_{0 *}\right)+H_{1 *}\left(\rho_{1}-\rho_{1 *}\right)+\alpha_{e e} \mathbf{e}: \mathbf{e}+\frac{1}{2} a_{e e} e^{2}-\frac{1}{2} a_{t t} \theta^{2}-a_{e t} e \theta \\
& -a_{e m 0} e\left(\rho_{0}-\rho_{0 *}\right)-a_{e m 1} e\left(\rho_{1}-\rho_{1 *}\right)-a_{t m 0} \theta\left(\rho_{0}-\rho_{0 *}\right)-a_{t m 1} \theta\left(\rho_{1}-\rho_{1 *}\right) \\
& +a_{m 0 m 1}\left(\rho_{0}-\rho_{0 *}\right)\left(\rho_{1}-\rho_{1 *}\right)+\frac{1}{2} a_{m 0 m 0}\left(\rho_{0}-\rho_{0 *}\right)^{2}+\frac{1}{2} a_{m 1 m 1}\left(\rho_{1}-\rho_{1 *}\right)^{2}
\end{aligned}
$$

where $\alpha_{e e}, a_{i j}$ are the characteristics of material $(i, j=\{e, m 0, m 1, t\}) ; e=\mathbf{e}: \mathbf{I}, \mathbf{I}$ is identity tensor.

Based on (13) using (12) we write down such explicit form of state equations for $\boldsymbol{\sigma}, S, H_{0}, H_{1}$

$$
\begin{aligned}
\boldsymbol{\sigma} & =2 \alpha_{e e} \mathbf{e}+\left[a_{e e} e-a_{e t} \theta-a_{e m 0}\left(\rho_{0}-\rho_{0 *}\right)-a_{e m 1}\left(\rho_{1}-\rho_{1 *}\right)\right] \mathbf{I}, \\
S-S_{*} & =a_{e t} e+a_{t t} \theta+a_{t m 0}\left(\rho_{0}-\rho_{0 *}\right)+a_{t m 1}\left(\rho_{1}-\rho_{1 *}\right), \\
H_{0}-H_{0 *} & =-a_{e m 0} e-a_{t m 0} \theta+a_{m 0 m 0}\left(\rho_{0}-\rho_{0 *}\right)+a_{m 0 m 1}\left(\rho_{1}-\rho_{1 *}\right), \\
H_{1}-H_{1 *} & =-a_{e m 1} e-a_{t m 1} \theta+a_{m 0 m 1}\left(\rho_{0}-\rho_{0 *}\right)+a_{m 1 m 1}\left(\rho_{1}-\rho_{1 *}\right) .
\end{aligned}
$$

Note that balance and constitutive equations are the basis for formulating of the solving system of equations. 


\section{The solving system of equations}

On the base of formulated above equations we write the solving equations system for various key functions.

Choosing as the key functions the displacement vector $\boldsymbol{u}$, the disturbances of skeleton and admixture densities $\rho_{0}-\rho_{0 *}, \rho_{1}-\rho_{1 *}$ and disturbance of temperature $\theta$, the key linearized system of the model we write in the form

$$
\begin{gathered}
\alpha_{e e} \nabla^{2} \boldsymbol{u}+\left(a_{e e}+\alpha_{e e}\right) \boldsymbol{\nabla}(\boldsymbol{\nabla} \cdot \boldsymbol{u})-a_{e t} \boldsymbol{\nabla} \theta-a_{e m 0} \boldsymbol{\nabla} \rho_{0}-a_{e m 1} \boldsymbol{\nabla} \rho_{1}=\rho_{*} \frac{\partial^{2} \boldsymbol{u}}{\partial \tau^{2}} \\
\begin{array}{r}
a_{t t} T_{*} \frac{\partial \theta}{\partial \tau}+a_{e t} T_{*} \frac{\partial(\boldsymbol{\nabla} \cdot \boldsymbol{u})}{\partial \tau}+a_{t m 0} T_{*} \frac{\partial \rho_{0}}{\partial \tau}+a_{t m 1} T_{*} \frac{\partial \rho_{1}}{\partial \tau} \\
=c_{s s} \nabla^{2} \theta-c_{s e} \nabla^{2}(\boldsymbol{\nabla} \cdot \boldsymbol{u})+c_{s 0} \nabla^{2} \rho_{0}+c_{s 1} \nabla^{2} \rho_{1}
\end{array} \\
\begin{array}{c}
\frac{\partial \rho_{1}}{\partial \tau}=c_{m s} \nabla^{2} \theta-c_{m e} \nabla^{2}(\boldsymbol{\nabla} \cdot \boldsymbol{u})+c_{m 0} \nabla^{2} \rho_{0}+c_{m 1} \nabla^{2} \rho_{1}, \\
g_{m m} a_{m 0 m 0} \nabla^{2} \rho_{0}+g_{m m} a_{m 0 m 1} \nabla^{2} \rho_{1}-g_{m m} a_{t m 0} \nabla^{2} \theta \\
-g_{m m} a_{e m 0} \nabla^{2}(\boldsymbol{\nabla} \cdot \boldsymbol{u})+\rho_{0}-\rho_{0 *}+\rho_{1}-\rho_{1 *}=0
\end{array}
\end{gathered}
$$

where $\rho_{*}=\rho_{0 *}+\rho_{1 *}$,

$$
\begin{gathered}
c_{s s}=\lambda_{s s}-\lambda_{s 0} a_{t m 0}, \quad c_{s e}=\lambda_{s 0} a_{e m 0}+\lambda_{s 1} a_{e m 1}, \quad c_{s 0}=\lambda_{s 0} a_{m 0 m 0}+\lambda_{s 1} a_{m 1 m 0}, \\
c_{s 1}=\lambda_{s 0} a_{m 0 m 1}+\lambda_{s 1} a_{m 1 m 1}, \quad c_{m s}=\left(\lambda_{s 1}-\lambda_{01} a_{t m 0}-\lambda_{11} a_{t m 1}\right) / T_{*}, \quad c_{m e}=\left(\lambda_{01} a_{e m 0}+\lambda_{11} a_{e m 1}\right) / T_{*}, \\
c_{m 0}=\left(\lambda_{01} a_{m 0 m 0}+\lambda_{11} a_{m 0 m 1}\right) / T_{*}, \quad c_{m 1}=\left(\lambda_{01} a_{m 0 m 1}+\lambda_{11} a_{m 1 m 1}\right) / T_{*} .
\end{gathered}
$$

Here have been taken into account the smallness of the temperature disturbance $\theta$ compared to the initial temperature $T_{*}$, the classical expression for translational momentum and the Cauchy relation

$$
\mathbf{e}=\frac{1}{2}\left(\boldsymbol{\nabla} \otimes \boldsymbol{u}+(\boldsymbol{\nabla} \otimes \boldsymbol{u})^{\mathrm{T}}\right)
$$

for strain tensor ( $\otimes$ denotes tensor product, superscript $T$ denotes transposition).

\subsection{Quasi-static and stationary states}

To describe the quasi-static processes the following system of equations is used

$$
\begin{gathered}
\alpha_{e e} \nabla^{2} \boldsymbol{u}+\left(a_{e e}+\alpha_{e e}\right) \boldsymbol{\nabla}(\boldsymbol{\nabla} \cdot \boldsymbol{u})-a_{e t} \boldsymbol{\nabla} \theta-a_{e m 0} \boldsymbol{\nabla} \rho_{0}-a_{e m 1} \boldsymbol{\nabla} \rho_{1}=0, \\
a_{t t} T_{*} \frac{\partial \theta}{\partial \tau}+a_{e t} T_{*} \frac{\partial(\boldsymbol{\nabla} \cdot \boldsymbol{u})}{\partial \tau}+a_{t m 0} T_{*} \frac{\partial \rho_{0}}{\partial \tau}+a_{t m 1} T_{*} \frac{\partial \rho_{1}}{\partial \tau}=c_{s s}^{\prime} \nabla^{2} \theta+c_{s 0}^{\prime} \nabla^{2} \rho_{0}+c_{s 1}^{\prime} \nabla^{2} \rho_{1}, \\
\frac{\partial \rho_{1}}{\partial \tau}=c_{m s}^{\prime} \nabla^{2} \theta+c_{m 0}^{\prime} \nabla^{2} \rho_{0}+c_{m 1}^{\prime} \nabla^{2} \rho_{1}, \\
g_{m m} a_{m 0 m 0}^{\prime} \nabla^{2} \rho_{0}+g_{m m} a_{m 0 m 1}^{\prime} \nabla^{2} \rho_{1}-g_{m m} a_{t m 0}^{\prime} \nabla^{2} \theta+\rho_{0}-\rho_{0 *}+\rho_{1}-\rho_{1 *}=0,
\end{gathered}
$$

where

$$
\begin{gathered}
c_{s s}^{\prime}=c_{s s}-\frac{c_{s e} a_{e t}}{a_{e e}+2 \alpha_{e e}}, \quad c_{s 0}^{\prime}=c_{s 0}-\frac{c_{s e} a_{e m 0}}{a_{e e}+2 \alpha_{e e}}, \quad c_{s 1}^{\prime}=c_{s 1}-\frac{c_{s e} a_{e m 1}}{a_{e e}+2 \alpha_{e e}}, \\
c_{m s}^{\prime}=c_{m s}-\frac{c_{m e} a_{e t}}{a_{e e}+2 \alpha_{e e}}, \quad c_{m 0}^{\prime}=c_{m 0}-\frac{c_{m e} a_{e m 0}}{a_{e e}+2 \alpha_{e e}}, \quad c_{m 1}^{\prime}=c_{m 1}-\frac{c_{m e} a_{e m 1}}{a_{e e}+2 \alpha_{e e}}, \\
a_{m 0 m 0}^{\prime}=a_{m 0 m 0}-\frac{a_{m 0}^{2}}{a_{e e}+2 \alpha_{e e}}, \quad a_{m 0 m 1}^{\prime}=a_{m 0 m 1}-\frac{a_{e m 0} a_{e m 1}}{a_{e e}+2 \alpha_{e e}}, \quad a_{t m 0}^{\prime}=a_{t m 0}+\frac{a_{e m 0} a_{e t}}{a_{e e}+2 \alpha_{e e}} .
\end{gathered}
$$

Mathematical Modeling and Computing, Vol.3, No. 1, pp. 12-22 (2016) 
The system of equations describing the steady state of binary solid solutions for the isothermal approximation written in terms of $\boldsymbol{u}, \rho_{0}, \rho_{1}$ has the form

$$
\begin{gathered}
\alpha_{e e} \nabla^{2} \boldsymbol{u}+\left(a_{e e}+\alpha_{e e}\right) \boldsymbol{\nabla}(\boldsymbol{\nabla} \cdot \boldsymbol{u})-a_{e m 0} \boldsymbol{\nabla} \rho_{0}-a_{e m 1} \boldsymbol{\nabla} \rho_{1}=0 \\
a \nabla^{2} \rho_{0}+\nabla^{2} \rho_{1}=0 \\
-\xi^{-2} \nabla^{2} \rho_{0}+\rho_{0}-\rho_{0 *}+\rho_{1}-\rho_{1 *}=0
\end{gathered}
$$

where

$$
\xi^{-2}=g_{m m}\left(a_{m 0 m 0}-a_{m 0 m 1} a\right)+\frac{g_{m m} a_{e m 0}}{a_{e e}+2 \alpha_{e e}}\left(a_{e m 1} a-a_{e m 0}\right), \quad a=\frac{c_{m 0}-c_{m e} a_{e m 0} /\left(a_{e e}+2 \alpha_{e e}\right)}{c_{m 1}-c_{m e} a_{e m 0} /\left(a_{e e}+2 \alpha_{e e}\right)} .
$$

If the densities $\rho_{0}, \rho_{1}$ and the stress tensor are chosen as the key functions then the solving system of equations has the form

$$
\begin{gathered}
a \nabla^{2} \rho_{0}+\nabla^{2} \rho_{1}=0 \\
-\xi^{-2} \nabla^{2} \rho_{0}+\rho_{0}-\rho_{0 *}+\rho_{1}-\rho_{1 *}=0 \\
\boldsymbol{\nabla} \cdot \boldsymbol{\sigma}=0, \quad \boldsymbol{\nabla} \times\left\{\boldsymbol{\nabla} \times\left[\boldsymbol{\sigma}-\frac{2 \alpha_{e e}}{3 a_{e e}+2 \alpha_{e e}}\left(\frac{a_{e e}}{2 \alpha_{e e}} \sigma-a_{e m 0} \rho_{0}-a_{e m 1} \rho_{1}\right) \mathbf{I}\right]\right\}^{\mathrm{T}}=0 .
\end{gathered}
$$

We see that the study of stationary mechanic-diffusion fields is reduced to a consistent determination of skeleton and admixture densities with the following determination of the motion vector and the tensors of stress and strain.

While formulating boundary value problems the system of equations (17) has to be supplied with appropriate boundary conditions. For mechanical fields we accept conventional conditions for stresses or displacements [15], and for the density of the skeleton we use the idea of geometric heterogeneity of actual body surface [10].

\section{Stationary state of two-component layer}

We consider an elastic layer that in Cartesian coordinate system $\{x, y, z\}$ occupies domain $|x| \leqslant l$. Let suppose that the layer is stretched with effort $\boldsymbol{F}=\left\{0,2 \sigma_{a} l, 0\right\}$ at infinity $y \rightarrow \infty$ and at the free of mechanical load surfaces $x=l, x=-l$ the constant nonzero values of skeleton $\rho_{0 a}$ and admixture $\rho_{1 a}$ densities are set.

Under considered external action the one-dimensional over $x$ coordinate situation is realized

$$
\boldsymbol{\sigma}=\boldsymbol{\sigma}(x), \quad \rho_{0}=\rho_{0}(x), \quad \rho_{1}=\rho_{1}(x) .
$$

Choosing the nonzero stress tensor components and the densities of solid solution components as solving functions the system (17) we write as

$$
\begin{gathered}
\frac{d^{2} \rho_{0}}{d x^{2}}-\xi^{2}\left(\rho_{0}-\rho_{0 *}+\rho_{1}-\rho_{1 *}\right)=0, \\
a \frac{d^{2} \rho_{0}}{d x^{2}}+\frac{d^{2} \rho_{1}}{d x^{2}}=0, \\
\frac{d \sigma_{x x}}{d x}=0, \quad \frac{d^{2} \sigma_{y y}}{d x^{2}}=\frac{d^{2} \sigma_{z z}}{d x^{2}}=-a_{0} \frac{d^{2} \rho_{0}}{d x^{2}}-a_{1} \frac{d^{2} \rho_{1}}{d x^{2}},
\end{gathered}
$$

where

$$
a_{i}=\frac{2 \alpha_{e e} a_{e m i}}{a_{e e}+2 \alpha_{e e}}, \quad i=1,2
$$

Mathematical Modeling and Computing, Vol. 3, No. 1, pp. 12-22 (2016) 
The problem of determination of equilibrium density distributions $\rho_{0}, \rho_{1}$ and principal components of stress tensor $\sigma_{\beta \beta}(\beta=\{x, y, z\})$ is reduced to solving the system of equations (18) under the conditions

$$
\rho_{0}=\rho_{0 a}, \quad \rho_{1}=\rho_{1 a}, \quad \sigma_{x x}=0
$$

at surfaces $x=l, x=-l$ of the layer and conditions for the main vectors of efforts and moments

$$
\int_{-l}^{l} \sigma_{y y}(x) d x=2 \sigma_{a} l, \quad \int_{-l}^{l} \sigma_{z z}(x) d x=0, \quad \int_{-l}^{l} x \sigma_{y y}(x) d x=0, \quad \int_{-l}^{l} x \sigma_{z z}(x) d x=0,
$$

in arbitrary cross-sections $y=$ const, $z=$ const.

The solution of formulated problem is

$$
\begin{gathered}
\rho_{0}(x)=\rho_{0 a}+\frac{\rho_{0 a}-\rho_{0 *}+\rho_{1 a}}{1-a}\left(\frac{\cosh (\vartheta x)}{\cosh (\vartheta l)}-1\right), \\
\rho_{1}(x)=\rho_{1 a}-a \frac{\rho_{0 a}-\rho_{0 *}+\rho_{1 a}}{1-a}\left(\frac{\cosh (\vartheta x)}{\cosh (\vartheta l)}-1\right), \\
\sigma_{y y}(x)=\sigma_{a}+\left(a a_{1}-a_{0}\right) \frac{\rho_{0 a}-\rho_{0 *}+\rho_{1 a}}{1-a}\left(\frac{\cosh (\vartheta x)}{\cosh (\vartheta l)}-\frac{\tanh (\vartheta l)}{\vartheta l}\right), \\
\sigma_{z z}(x)=\sigma_{y y}(x)-\sigma_{a}, \quad \sigma_{x x}(x)=0,
\end{gathered}
$$

where

$$
\vartheta=\sqrt{1-a} \xi .
$$

It is accepted in this case that the density of admixtures in the reference state is equal to zero.

For the admixture density at the middle surface of a thick layer from (21) we write

$$
\rho_{1}(0)=\frac{a\left(\rho_{0 a}-\rho_{0 *}\right)+\rho_{1 a}}{1-a} .
$$

Accounting that $\rho_{0 a}-\rho_{0 *}<0$ and densities are positive, we conclude that

$$
a<0 .
$$

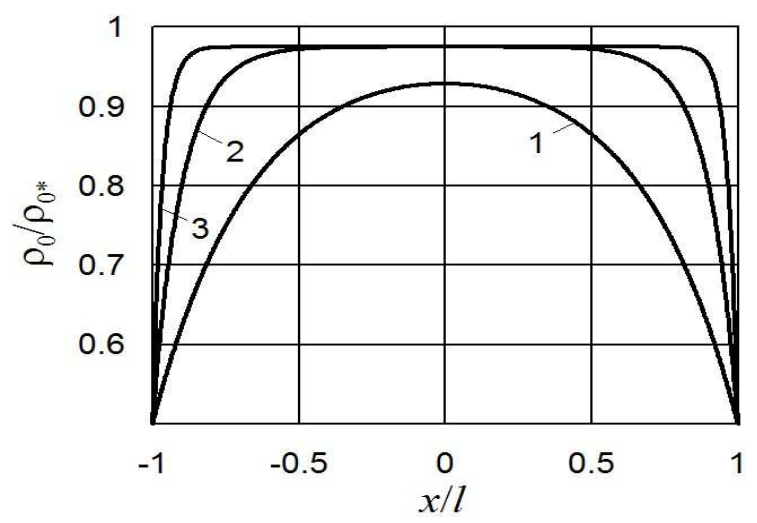

Fig. 1. Skeleton density in the layer.

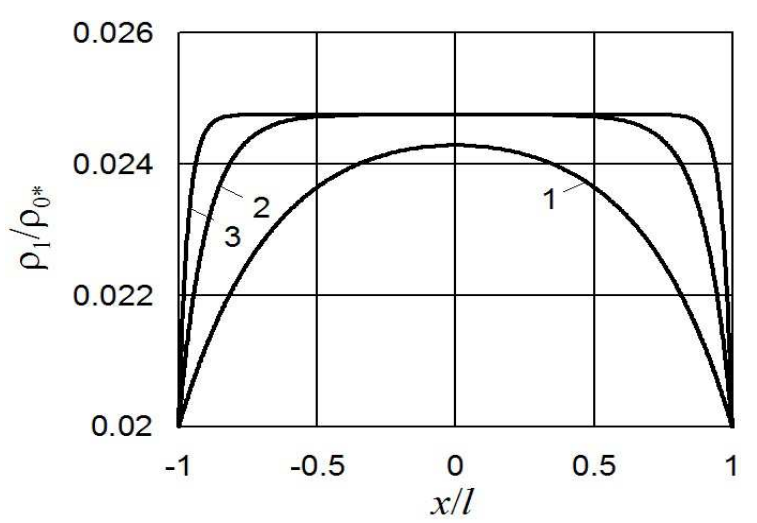

Fig. 2. Admixture density in the layer.

Results of numerical analysis of mechanic-diffusive fields under force load absence $\left(\sigma_{a}=0\right)$ are shown in Fig. 1-6. In the first figure the skeleton density $\rho_{0} / \rho_{0 *}$ is plotted for $\xi l=3 ; 10 ; 30$ (graphs 1-3 respectively), $\rho_{0 a} / \rho_{0 *}=0.5, \rho_{1 a} / \rho_{0 *}=0.02, a=-0.01$. One can see that the distribution of the skeleton density is similar to the density distribution in the layer without admixtures [7]. The magnitude of the admixtures influence on the skeleton density is mainly determined by the parameter $a$. 
Depending on this value the admixtures presence in the body can lead to significant changes in the skeletal density in the inner regions of the body.

In the Fig. 2 the admixture density $\rho_{1} / \rho_{0 *}$ is plotted in the layer for $\xi l=3 ; 10 ; 30$ (graphs $1-3$ respectively), $\rho_{0 a} / \rho_{0 *}=0.5, \rho_{1 a} / \rho_{0 *}=0.02, a=-0.01$. One can see that the distribution of the admixture is analogous to the distribution of the skeleton density.

Figs. 3 and 4 show skeleton $\rho_{0} / \rho_{0 *}$ and admixtures $\rho_{1} / \rho_{0 *}$ densities at the middle surface of the layer dependence of parameter $a$ for $\xi l=3,5$ (curves 1,2$), \rho_{1 a} / \rho_{0 *}=0.02$.

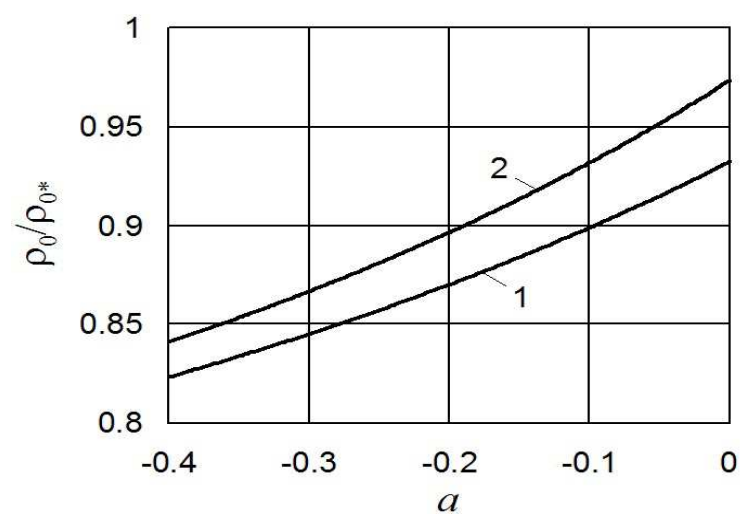

Fig. 3. Skeleton density dependence on $a$ at $x=0$.

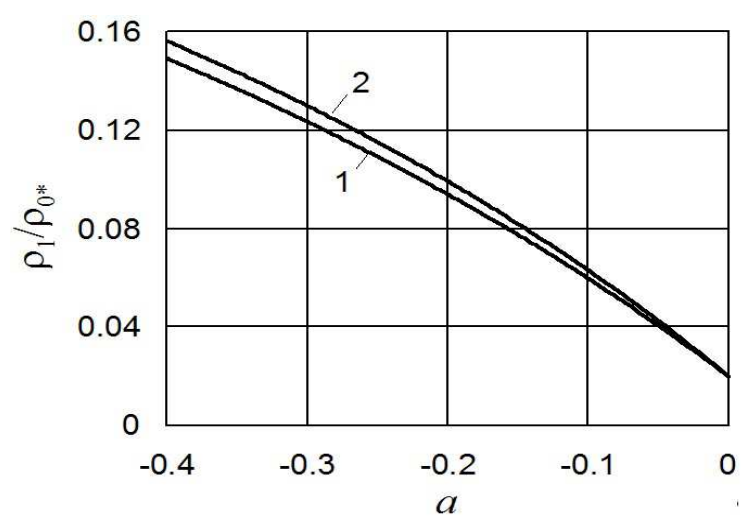

Fig. 4. Admixture density dependence on $a$ at $x=0$.

Fig. 5 shows stresses $\sigma_{y y} / \sigma_{0}\left(\sigma_{0}=a_{0} \rho_{0 *}\right)$ distribution in the layer for $\xi l=3,10,30$ (graphs 1-3 respectively), $\rho_{0 a} / \rho_{0 *}=0.5, \rho_{1 a} / \rho_{0 *}=0.02, a=-0.01, a_{1} / a_{0}=0.1$. The largest stretching stresses in the body are the stresses $\sigma_{y y}=\sigma_{z z}$ at the outer surface of the layer.

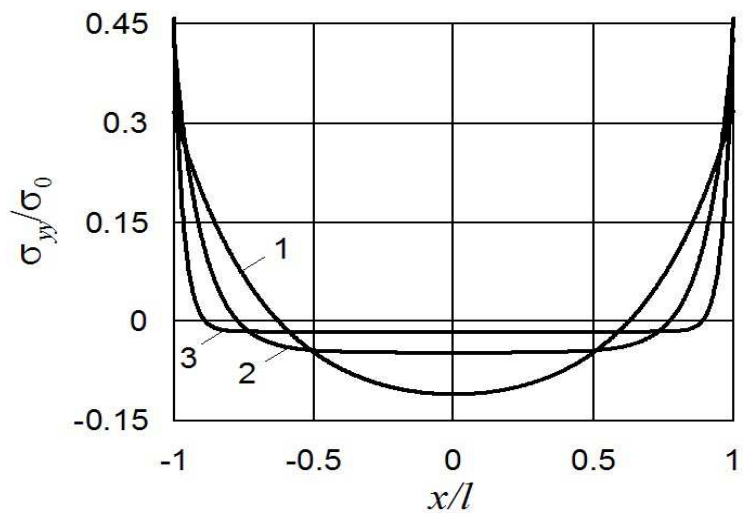

Fig. 5. Stress distribution in the layer.

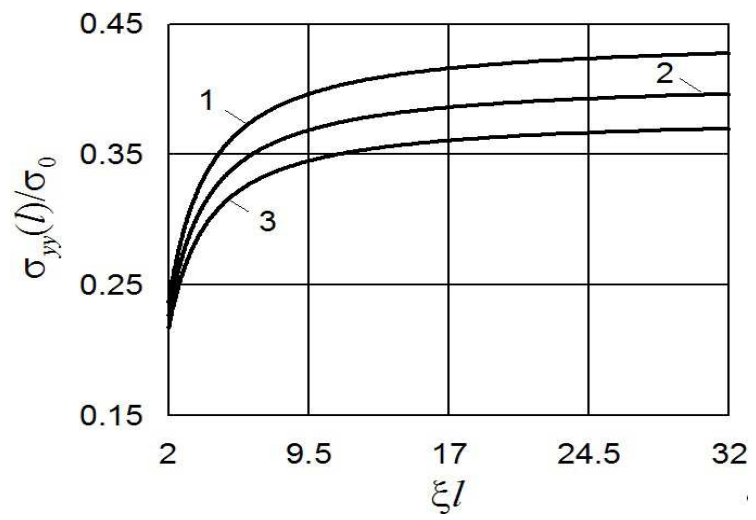

Fig. 6. Surface stresses dependence on layer thickness.

The size effect (dependence on layer thickness) is inherent to surface stresses. This is illustrated in Fig. 6, which shows the dependence of $\sigma_{y y}( \pm l) / \sigma_{0}$ on the parameter $\xi l$ when $a=-0.1,-0.2,-0.3$ (curves 1-3), $\rho_{0 a} / \rho_{0 *}=0.5, \rho_{1 a} / \rho_{0 *}=0.02, a_{1} / a_{0}=0.1$.

\subsection{Size effect of strength}

Let us use the obtained above relations to study the effect admixtures on the value of the power load leading to the layer fracture. We suppose that the layer fractures immediately if the main principal stresses reach its critical value $\sigma_{p}$ at least in one point of the layer. The largest of stretching stresses is the stress $\sigma_{y y}$ at surfaces $x= \pm l$, which according to (21) is described by formula

$$
\sigma_{y y}( \pm l)=\sigma_{a}+\left(a a_{1}-a_{0}\right) \frac{\rho_{0 a}-\rho_{0 *}+\rho_{1 a}}{1-a}\left(1-\frac{\tanh (\vartheta l)}{\vartheta l}\right) .
$$


According to the first classical theory of strength [13], the intensity of the power load leading to the layer fracture is

$$
\sigma_{a}^{c r}=\sigma_{p}-\left(a a_{1}-a_{0}\right) \frac{\rho_{0 a}-\rho_{0 *}+\rho_{1 a}}{1-a}\left(1-\frac{\tanh (\vartheta l)}{\vartheta l}\right) .
$$

Taking for the intensity of the power load, leading to fracture of a thick layer without admixture, the expression

$$
\sigma_{+}=\sigma_{p}+a_{0}\left(\rho_{0 a}-\rho_{0 *}\right)
$$

formula (23) takes the form

$$
\sigma_{a}^{c r}=\sigma_{+}-a_{0}\left(\rho_{0 a}-\rho_{0 *}\right)-\left(a a_{1}-a_{0}\right) \frac{\rho_{0 a}-\rho_{0 *}+\rho_{1 a}}{1-a}\left(1-\frac{\tanh (\vartheta l)}{\vartheta l}\right) .
$$

This formula can be interpreted as the one that describes the size effect of tensile strength and impact of admixture on it.

Fig. 7 shows dependence of $\sigma_{a}^{c r} /\left(a_{0} \rho_{0 *}\right)$ on the layer thickness for $a=-0.1,-0.2,-0.3$ (graphs 1-3 respectively), $\sigma_{+} /\left(a_{0} \rho_{0 *}\right)=0.3, \rho_{0 a} / \rho_{0 *}=0.5, \rho_{1 a} / \rho_{0 *}=0.02, a_{1} / a_{0}=0.1$.

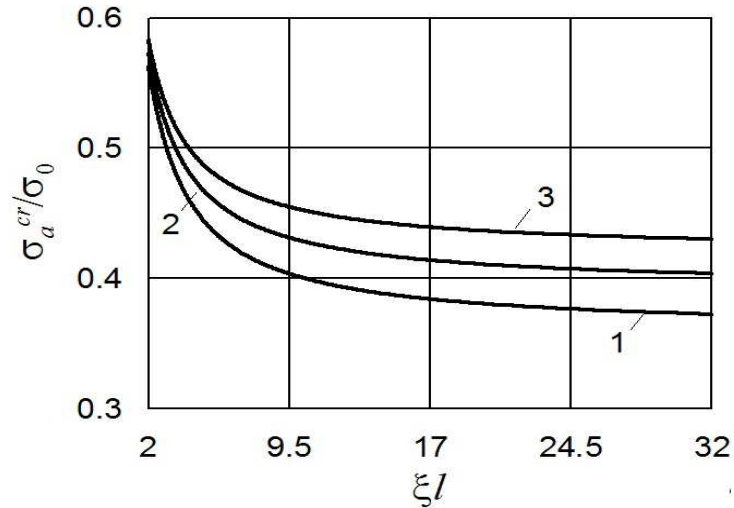

Fig. 7. Size effect of strength.

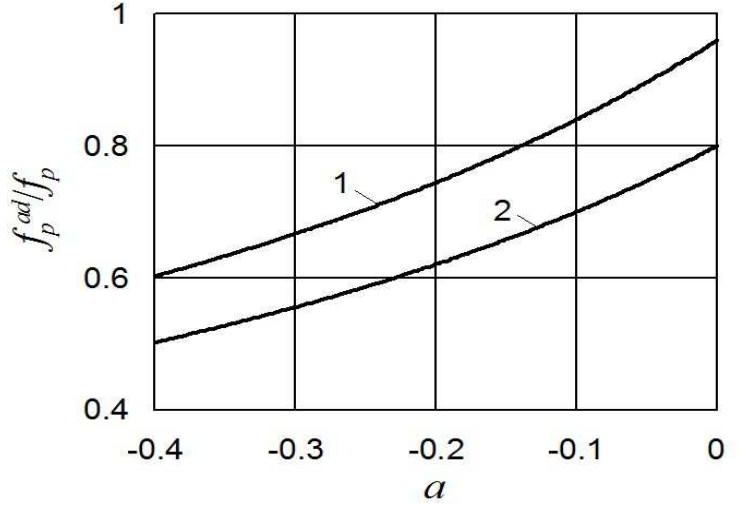

Fig. 8. Surface tension in halfspace dependence on $a$.

\subsection{Surface tension}

Surface tension $f_{p}$ in the body free from the power load is an integral characteristic of nearsurface stretching stresses [14]. From the condition $\sigma_{y y}\left(x_{a}\right)=0$ we find the point $x_{a}$ of transition of stretching nearsurface stresses into compressive ones in the layers with thickness $\vartheta l$ such that $\exp (\vartheta l) \gg \vartheta l$

$$
x_{a}=l\left(1-\frac{\ln (\vartheta l)}{\vartheta l}\right) .
$$

Considering this relation in the formula

$$
f_{p}=-\left(a a_{1}-a_{0}\right) \frac{\rho_{0 a}-\rho_{0 *}+\rho_{1 a}}{1-a} \frac{l \sinh \left(\vartheta x_{a}\right)-x_{a} \sinh (\vartheta l)}{\vartheta l \cosh (\vartheta l)}
$$

for surface tension we obtain

$$
f_{p}=\left(a a_{1}-a_{0}\right) \frac{\rho_{0 a}-\rho_{0 *}+\rho_{1 a}}{\vartheta(1-a)}\left(1-\frac{1}{\vartheta l}(1+\ln (\vartheta l))\right) .
$$

Mathematical Modeling and Computing, Vol. 3, No. 1, pp. 12-22 (2016) 
With layer thickness increase the surface tension increases, heading for the value of the surface tension in half-space saturated with admixtures

$$
f_{p}^{\infty}=\left(a a_{1}-a_{0}\right) \frac{\rho_{0 a}-\rho_{0 *}+\rho_{1 a}}{\vartheta(1-a)},
$$

that is it shows the size effect.

Fig. 8 shows dependence on the parameter $a$ of the ratio surface tension in saturated half-space to surface tension in half-space without admixtures $\rho_{0 a} / \rho_{0 *}=0.5, \rho_{1 a} / \rho_{0 *}=0.02,0.1$ (graphs 1-2 respectively), $a_{1} / a_{0}=0.1$.

Further research is needed to study the impact of the geometric non-homogeneity of the body surface on the revealed effects.

\section{Conclusions}

Using the methods of irreversible thermodynamics the key systems of equations describing the mechanic, thermal and diffusive processes in two-component solid solution are formulated. The systems take account of structural nonhomogeneity of the skeleton subsystem. As key functions the skeleton and admixture densities as well as displacement vector (strain tensor) are chosen. The boundary conditions of corresponding boundary value problems include classical conditions for mechanical components (stresses, displacements) and the boundary condition for skeleton subsystem density accounts for the roughness of real body surface. Methods of steady state studying are consistent determining of skeleton and admixture densities and the following search for mechanical fields.

The presence of admixture in the body leads to a change in the characteristic size of the nearsurface nonhomogeneity, and thus to change of the scale of size effects of thin film strength, surface tension and so on.

In the free of power load layer the greatest stress is the stretching stress at the layer surface. When moving away from the body surface the stress reduces and became compressive near the middle surface of the thin film. The presence of admixture in the body does not change the picture of the stresses distribution however leads to changes in the values of stresses. The presence of admixture does not change the picture of size effects in thin film.

[1] Stark J. P. Solid state diffusion. Wiley. 237 p. (1976).

[2] Borg R. J., Dienes G. J. An Introduction to Solid State Diffusion. ACADEMIC PRESS Inc. 360 p. (1988).

[3] Wilkinson D. S. Mass transport in solids and fluids. Cambridge University Press. 270 p. (2000).

[4] Barton C. Prorok, Yong Zhu, Horacio D. Espinosa, Zaoyang Guo, Zdenek P. Bazant, Yufeng Zhao, Boris I. Yakobson. Micro- and Nanomechanics, in Encyclopedia of Nanoscience and Nanotechnology, Edited by H. S. Nalwa. Vol. 5, 555-600 (2004).

[5] Mazurkiewicz A., Dobrodziej J., Poteralska B. Nanonauki i nanotechnologie: stan i perspektywy rozwoju. W-wo Instytutu Technologii Eksploatacji, Radom. 605 s. (2007).

[6] Burak Y., Nahirnyj T., Tchervinka K. Local gradient thermomechanics. Encyclopedia of Thermal Stresses. 2794-2801 (2014).

[7] Nahirnyj T., Tchervinka K. Basics of mechanics of local non-homogeneous elastic bodies. Bases of nanomechanics II. Lviv, Rastr-7. 168 p. (2014).

[8] Nahirnyj T., Tchervinka K. Mathematical modeling of structural and near-surface non-homogeneities in thermoelastic thin films. Int. J. Eng. Sci. 91, 49-62 (2015).

[9] Nahirnyj T., Tchervinka K. Thermodynamical models and methods of thermomechanics taking into account near-surface and structural nonhomogeneity. Bases of nanomechanics I. Lviv, Spolom. 264 p. (2012).

[10] Nahirnyj T., Chervinka K., Boiko Z. On the choice of boundary conditions in problems of the local gradient approach in thermomechanics. Journal of Mathematical Sciences. 186, n. 1, 130-138 (2012). 
[11] de Groot S. R., Mazur P. Non-equilibrium Thermodynamics. North-Holland Publishino Company, Amsterdam. $457 \mathrm{p}$. (1962).

[12] Münster A. Chemische Thermodynamik. Berlin, Akademie Verlag. 295 p. (1969).

[13] Fracture Mechanics and Strength of Materials: Handbook: in 4 vol. / Ed. Panasyuk V. V. Kyev, Nauk. dumka. Vol. 3: Characteristics of short-time crack resistance of materials and methods of their determination. 436 p. (1988).

[14] Lambert P. Surface Tension in Microsystems. Engineering Below the Capillary Length. Springer-Verlag, Berlin. 327 p. (2013).

[15] Timoshenko S. P., Goodier J. N. Theory of Elasticity. McGraw-Hill International Editions (1970).

\title{
До моделювання впливу домішок на розмірні ефекти у тонкій плівці
}

\author{
Боженко Б. Л. ${ }^{1,2}$, Нагірний Т. С. ${ }^{1,3}$, Червінка K. А. ${ }^{4}$ \\ ${ }^{1}$ Центр математичного моделювання ІППММ ім. Я. С. Підстригача \\ вул Дю. Дудаєва, 15, 79005, Львів, Україна \\ ${ }^{2}$ Механіко-машинобудівний факультет, Університет міста Зелена Гура \\ вул. проф. Шафрана 4, 65-516, Зелена Гура, Польща \\ 3 Технологічний університет міста Ополе \\ вул. Любощищька 3, 45-036, Ополе, Польща \\ 4 Львівсъкий начіональний університет імені Івана Франка \\ вул. Університетсъка, 1, Лъвів 79000, Україна
}

\begin{abstract}
Сформульовано ключові системи рівнянь, що описують поведінку та стаціонарний стан структурно неоднорідних двокомпонентних твердих розчинів. За ключові функції прийнято густини скелету та домішок, а також тензор напруження (вектор переміщення). На цій основі вивчено приповерхневу неоднорідність та розмірні ефекти поверхневих напружень та інтенсивності силового навантаження, що приводить до руйнування тонкої плівки.
\end{abstract}

Ключові слова: тверді розчини, приповерхнева неоднорідність, тонкі плівки, розмірні ефекти.

2000 MSC: 74A15, 74A50, 74E05, 74K35, 74N25

УдК: $[539.3+532.72]: 532.68$

Mathematical Modeling and Computing, Vol. 3, No. 1, pp. 12-22 (2016) 